\title{
Phenomena of Parallel Discharges and Flashovers in Lightning Triggered to Conventional and Non-conventional Lightning Rods
}

\author{
Yi-Jun Zhang $* * * *$ Non-member \\ Ming-Li Chen $* * \quad$ Non-member \\ Ya-Ping $\mathrm{Du}^{* *} \quad$ Non-member \\ Xin-Sheng Liu*** Non-member
}

\begin{abstract}
Experiments of rocket-triggered lightning to a conventional lightning rod and a non-conventional Semiconductor Lightning Eliminator (SLE) were conducted in summers of 1998 and 1999 in southern China. Totally 16 lightning flashes were triggered and measured successfully. The measurements included photographs, currents and electrical fields. From the 5 lightning flashes triggered in altitude in 1998, it was found that these flashes tended to strike at the $4 \mathrm{~m}$ high conventional lightning rod rather than the $6 \mathrm{~m}$ high SLE located just $5 \mathrm{~m}$ away from the former. From the 11 lightning flashes triggered dedicatedly to the SLE in 1999, it was fund that there were usually a phenomenon of parallel discharges between two or more SLE rods occurring during the developing stage of lightning. In addition, there were always flashovers occurred along the SLE rods struck by lightning. Current measurements on the grounding path of the SLE have been succeeded for only one case out of five struck the SLE, probably due to side-paths caused by flashovers. The peak current measured for that case was about 6.6 kilo-amperes. The results show that the SLE is neither superior to a traditional lightning rod in terms of provision of lightning attachment points and paths for the lightning current to flow into ground, nor capable to eliminate any possibility of lightning. The lightning current-limiting function of the SLE declared by the manufacturer was not confirmed by these experiments.
\end{abstract}

Keywords : triggered lightning, non-conventional lightning rod, parallel discharge, flash over

\section{Introduction}

In recent years, various nonconventional lightning protection systems have been deployed and applied to limit damage from lightning. However, there has been controversy about their working principle as well as their effectiveness in practice superior to conventional lightning rods. One typical example is the so-called Semi-conductor Lightning Eliminator (SLE) developed and applied in China recent years. The SEL is composed of several semiconductor rods distributed radically on a conductive base. Each rod is $5 \mathrm{~m}$ long with 4 metallic tips on its top and has a resistance of 35 kilo-ohms ${ }^{(1)}$. The manufacturer declared that the SLE can eliminate upward going lightning discharge and lighten the damage of downward going lightning discharge due to its current-limiting function.

There are two basic approaches in examining a lightning protection facility. One is by means of long-gap discharges in high-voltage laboratories ${ }^{(2)-(4)}$. The laboratory gap discharge, however, is considerably smaller in both the scale and current than the natural lightning. In addition to the laboratorial test, the artificially triggered lightning technique, especially the triggered lightning in altitude provides a unique means for investigating the function and effectiveness of a lightning protection facility in

* Laboratory of Lightning Physics and Protection, Chinese Academy of Meteorological Sciences

No.46 Zhongguancun Nandajie, Haidian, Beijing, China

** Department of Building Services Engineering, The Hong Kong Polytechnic University Hung Hom, HK, China

*** Cold and Arid Regions Environmental \& Engineering Research Institute, Chinese Academy of Sciences

260 W. Dinggang Road, Lanzhou, China field ${ }^{(5)-(7)}$

To test and compare the function of both the conventional lightning rod and the nonconventional SLE in field, experiments of triggered lightning were conducted in southern China in the summer of 1998 and 1999. This paper briefly reports the experiment results and some interesting phenomenon observed during the triggering lightning campaign.

\section{Instrumentation and Measurements}

In 1998, the so-called altitude-triggering lightning technique was adopted to compare the lightning acceptance between the SLE and conventional lightning rod. The conventional lighting rod was a $4 \mathrm{~m}$ high copper rod, with 6 launchers placed symmetrically around it (Figure 1). The SLE system was located 5m away to the right of the conventional lightning rod. The SLE was composed of

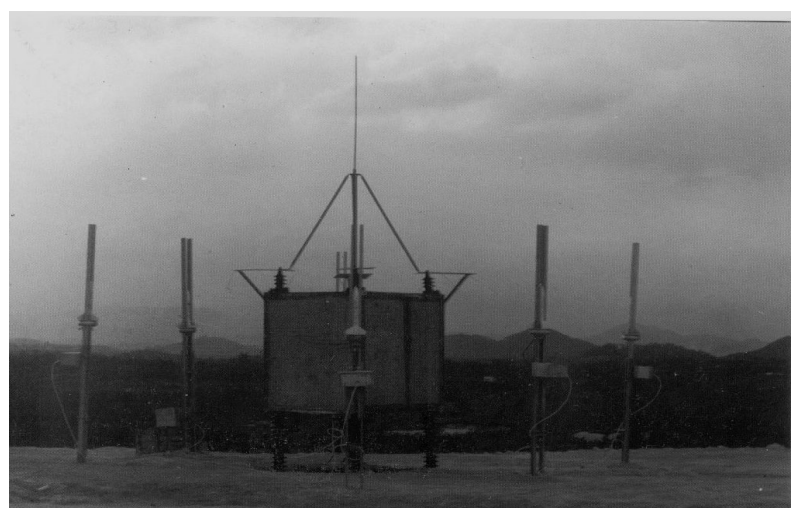

Fig. 1. The deployment of the conventional lightning rod and the rocket launchers around the lightning rod in 1998 
9 rods arranged orthogonally in two directions and was mounted on the ground through 4 isolators. Each rod was made of a special material, being $5 \mathrm{~m}$ in length and 35 kilo-ohms in resistance, and had 4 metal tips with $20 \mathrm{~cm}$ in length on its top. The resultant height of the SLE was about $6 \mathrm{~m}$, which is $2 \mathrm{~m}$ higher than the conventional lightning rod. The altitude-triggering lightning technique used in the experiment was similar to that employed in the triggered lightning experiment at Camp Blanding, Florida ${ }^{(8)}$. After launching the rocket first spooled out about $100 \mathrm{~m}$ of electrically insulated nylon cable from the bobbin attached to the rocket tail, and then a steel wire $(0.2 \mathrm{~mm}$ in diameter $)$ was unreeled. Photography and electrical field measurements were carried out at two sites. Site 1 was about $60 \mathrm{~m}$ away from the launchers and site 2 about $1.3 \mathrm{~km}$ away from the launcher. Details of the measurement arrangements were given in that of $\mathrm{Chen}^{(9)}$.

In 1999, the experiment was focused on testing the SLE itself and the current measuring system. Figure 2 shows the experiment setup. A set of SLE similar to that used in 1998 was mounted on an $8.5 \mathrm{~m}$ high steel tower through 4 isolators and was grounded by using a steel pipe down through the center of the tower. To facilitate the data analysis, we symbolized the SLE rods with numbers 1, 2, 3, 4 and 5 and letters a, b, c, $d$ and e respectively as shown in the figure. The rockets used to trigger lightning were placed around the tower on the ground. The steel wire trailing by each rocket was connected to one of the SLE rods via a $6 \mathrm{~m}$ long nylon cable to ensure the SLE of being struck by triggered lightning. A Rogowski coil and a shunt with a resistance of 5.47 milli-ohms were used to measure the lightning current flowing on the grounding steel pipe at the center of the tower. The signal from the Rogowski coil was recorded directly by an oscilloscope at a sampling rate of $400 \mathrm{kHz}$ and a recording length of 150 milliseconds per event. The output of the shunt was transmitted through an optical fiber system to a tent located $90 \mathrm{~m}$ away from the SLE, and was recorded there on an oscilloscope at a sampling rate of $5 \mathrm{MHz}$ and a recording length of 3.2 seconds per event. The electric field changes produced by the triggered
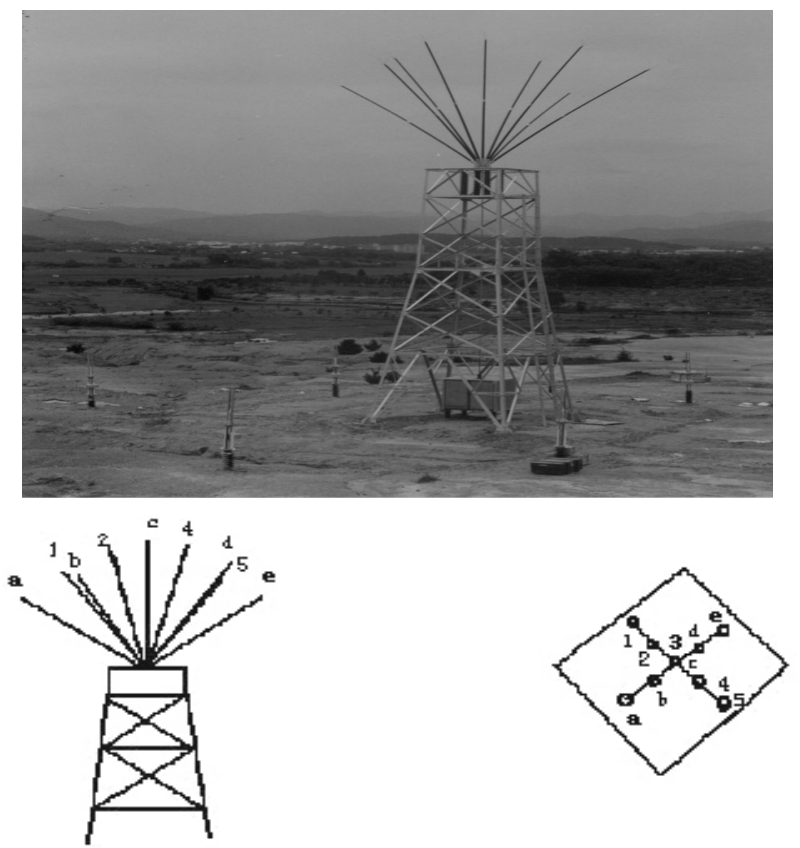

Fig. 2. The deployment of the experiment in 1999 (SLE rod 3 and $\mathrm{c}$ are the same one) lightning were measured simultaneously at two sites $(60 \mathrm{~m}$ and $1.3 \mathrm{~km}$ away from the SLE respectively) by using two identical flat-plate slow antenna systems with a band-width of $4 \mathrm{~Hz} \sim 1.5$ $\mathrm{MHz}$, a sampling rate of $12.5 \mathrm{MHz}$, a digital revolution of 12 bit and a recording length of 2 Mega words per event). The optical images of lightning channel were recorded by using still cameras and video cameras in two orthogonal directions. A high speed video camera with a speed of 1000 frames per second was placed $1.3 \mathrm{~km}$ away from the SEL to observe the development of the whole lightning channel.

\section{Data Analysis and Results}

3.1 Attachment Process of Triggered Lightning to the Lightning Rod In 1998, total of 5 successfully triggered lightning flashes were obtained on 22 August during a period of 20 minutes when the electric field intensity on the ground was about -6 to $-10 \mathrm{kV} / \mathrm{m}$, corresponding to negative charge overhead. Table 1 is a summary of these flashes. Based on detailed analysis of the optical and electrical measurements in that of $\mathrm{Chen}^{(9)}$, it was found that these five triggered lightning flashes have similar developing process as following. When the rocket reaches a sufficient height, a bi-directional leader system initiates from the two extremities of the wire unreeled from the rocket. That is a positive leader is initiated from the top of wire and propagates toward the cloud negatively charged, while a downward negative leader is initiated from the bottom of wire and propagates toward the ground. When the downward negative leader approaches the ground, an upward connecting positive leader is stimulated from the ground or the lightning rod. A mini-return stroke occurs when the downward negative leader meets the upward connecting leader. Then the mini-return stroke propagates along the trail of the melt wire and the positive leader previously initiated from the top of wire towards to the cloud. When the mini-return stroke wave reaches the charge center inside the cloud, a continuous current process is initiated. Following the continuous current process, some of downward dart leader/upward return stroke sequences traverse the same path. It is such a special developing process of altitude-triggered lightning that provides a close simulation of the downward leader and ground attachment processes in natural lightning.

Two triggered lightning discharges among them, 9802 and 9804, have struck the lightning rod. Figure 3(a) shows a still picture of case 9804 taken $1.3 \mathrm{~km}$ away from the lightning rod. The bright straight part with a length of about $250 \mathrm{~m}$ of the lightning channel is formed by the vaporized residue of the wire and the other parts are the lightning channel in the air. As seen from the figure, the very lower part of the lightning channel has changed the direction from a relative vertical one into a slant one at a height of about 30 $\mathrm{m}$ above ground. This lower $30 \mathrm{~m}$ channel bent is eventually due to an attachment process of the triggered lightning to the lightning rod there. Figure 3 (b) shows the still picture of case 9802 taken

Table 1. Summary of the 5 triggered lightning flashes in 1998

\begin{tabular}{|l|l|l|l|l|}
\hline Flash No. & $\begin{array}{l}\text { Triggered } \\
\text { Time }\end{array}$ & $\begin{array}{l}\text { Triggered } \\
\text { Height(m) }\end{array}$ & $\begin{array}{l}\text { Return } \\
\text { Strokes }\end{array}$ & $\begin{array}{l}\text { Attached to } \\
\text { Lightning Rod }\end{array}$ \\
\hline 9801 & $16: 41: 48$ & 276 & 2 & No \\
\hline 9802 & $16: 45: 55$ & 553 & 4 & Yes \\
\hline 9803 & $16: 52: 22$ & 387 & 0 & No \\
\hline 9804 & $16: 55: 25$ & 276 & 0 & Yes \\
\hline 9805 & $17: 00: 48$ & 332 & 9 & No \\
\hline
\end{tabular}


$60 \mathrm{~m}$ away from the lightning rod. It can be seen that when lightning path is approaching to the ground, it has changed the direction from vertical to slant towards the lightning rod at a height of about $15 \mathrm{~m}$ above and a horizontal distance of about 14 $\mathrm{m}$ away from the tip of the lightning rod. Three return strokes of this flash have changed the direction once again when they are at the height of $6 \mathrm{~m}$ above ground and have connected to the lightning rod eventually, and one return stroke has struck a rocket launcher $2 \mathrm{~m}$ away from the lightning rod. The change of the lightning path near the ground is obviously due to the attachment process between the lightning rod / launcher and the downward leader preceding each of the return strokes. It is worthwhile to mention that SLE was at just $5 \mathrm{~m}$ away from the lightning rod and its top was taller than that of the lightning rod, but the triggered lightning would rather choose the lightning rod to strike. Nevertheless, some discharging sparks have been observed above the SLE rods when the electric field intensity on ground is more than $-4 \mathrm{kV} / \mathrm{m}$.

3.2 Parallel Discharges between SLE Rods In 1999, the triggered lightning experiment was dedicatedly conducted to test the SLE. The general information of the experiment is summarized in Table 2 . Totally 11 triggered lightning events with meaningful data recorded (photographs, electrical field changes or/and currents) have been obtained. The range of electric fields on ground just before the launching of rockets was between -9 and $-18 \mathrm{kV} / \mathrm{m}$. The triggering heights were in a wide range between 25 $\mathrm{m}$ and $509 \mathrm{~m}$. Among the 1 levents, there are 8 cases with bright main discharging channels formed and 5 out of the 8 struck onto

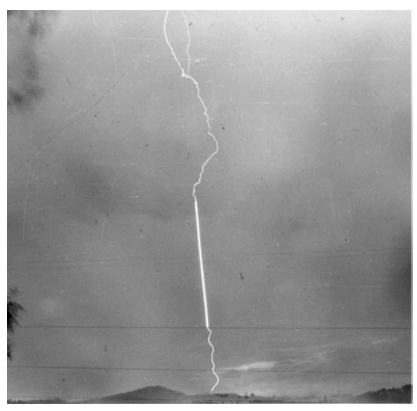

(a)

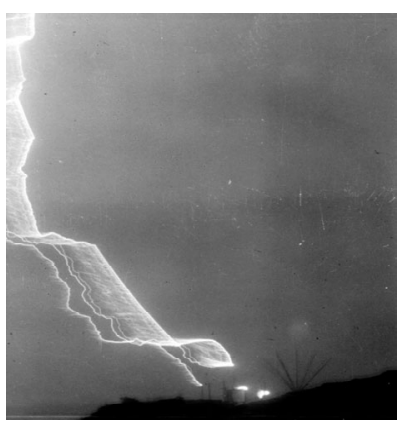

(b)
Fig. 3. The still camera pictures of (a) event 9804 taken at 1.3 $\mathrm{km}$ away from the lightning rod and (b) event 9802 taken at $60 \mathrm{~m}$ away from the lightning rod, showing the attachment process of lightning on to the lightning rod the SLE. The other 3 cases have no main discharging channel formed but have local discharging sparks appeared at the SLE rods.

Figure 4 shows the video pictures taken $60 \mathrm{~m}$ away from the launcher for event 9902 that has struck the SLE with main discharging channels formed. A local parallel discharge firstly occurred between the SLE rods 4 and 5 after the rocket was launched (Fig. 4(a)). One second later, the main lightning channel was formed and struck on another rod with flashovers occurred along the rod surface (Fig. 4(b)). Unfortunately the current of the discharge was not obtained probably due to that the current flew into the ground via the tower legs rather than the grounding pipe that was equipped with the current recording system.

It is interesting that for the 3 events 9905, 9909 and 9910, although no main discharging channels were formed, the so-called parallel discharges between SLE rods and flashovers along SLE rod surfaces have been still observed. In event 9905, the parallel discharge occurred between the rods $\mathrm{c}$ and d even lasted about 3.42 seconds. In event 9910, spark discharges at the tip of and flashovers along the surface of the rod e were observed by using a video camera at $60 \mathrm{~m}$ away. The corresponding currents with small magnitude for the sparks in event 9910 were also recorded by the Rogowski coil systems (Fig. 5(a)). There are three pulses in the current waveform shown in the figure. The pulse A has a width of about $1.2 \mathrm{~ms}$ and a peak of 3.8 amperes (Fig. 5(b)). The pulse B appears about $130 \mathrm{~ms}$ later after the pulse A, with a width of $0.1 \mathrm{~ms}$ and a peak of 4 amperes (Fig. 5(c)). The pulse $\mathrm{C}$ occurs about $70 \mathrm{~ms}$ later after the pulse $\mathrm{B}$, with a width of more than 25

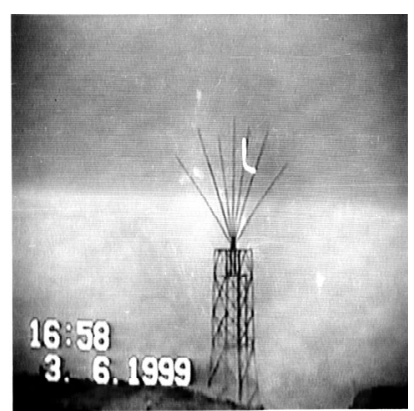

(a)

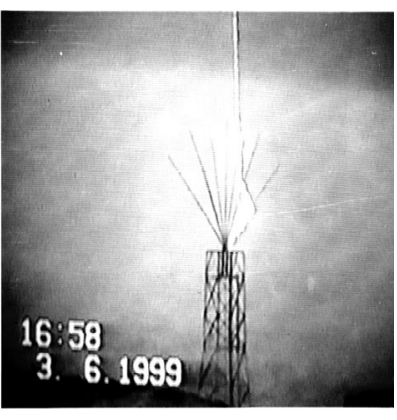

(b)
Fig. 4. Video pictures for event 9902, showing (a) the parallel discharge between rods 4 and 5 prior to the main discharge, and (b) the main discharge channel and the flashovers along the SLE rod formed 1 second later after the (a)

Table 2. Summary of the triggered lightning flashes for testing the SLE in 1999

\begin{tabular}{|c|c|c|c|c|c|c|c|c|}
\hline $\begin{array}{l}\text { Flash } \\
\text { No. }\end{array}$ & Time, date & $\begin{array}{c}\text { Wire spooled } \\
\text { (Nylon + wire) }\end{array}$ & $\begin{array}{c}\text { Main } \\
\text { channel }\end{array}$ & $\begin{array}{c}\text { Struck } \\
\text { SLE }\end{array}$ & $\begin{array}{l}\text { SLE responses } \\
\text { (type: rod) }\end{array}$ & $\begin{array}{c}\text { Triggered } \\
\text { Height }\end{array}$ & $\begin{array}{l}\text { Return } \\
\text { Strokes } \\
\end{array}$ & $\begin{array}{c}\text { Current } \\
\text { (kA) }\end{array}$ \\
\hline 9901 & 16:55:43, Jun 3 & $4 m+570 m$ & yes & $\operatorname{rode}$ & F: e & $33 \mathrm{~m}$ & 0 & \\
\hline 9902 & $16: 57: 47$, Jun 3 & $5 m+630 m$ & yes & $\operatorname{rod} \mathrm{c}$ & F: c, PD: $4 \& 5$ & $145 \mathrm{~m}$ & 0 & \\
\hline 9903 & 17:02:35, Jun 3 & $4 m+800 m$ & yes & no & LD: SLE base & & - & \\
\hline 9904 & 17:10:00, Jun 3 & $90 m+615 m$ & yes & no & No & & 2 & \\
\hline 9905 & 20:07:50, Jun 18 & $6 m+490 m$ & no & - & $\begin{array}{l}\text { PD: c \& b, LD: } \\
\text { SLE base }\end{array}$ & & - & \\
\hline 9906 & 21:18:38, Jul 10 & $6 m+490 m$ & yes & $\operatorname{rod} \mathrm{c}$ & $\mathrm{F}: \mathrm{c}$ & $445 \mathrm{~m}$ & 2 & \\
\hline 9907 & 21:54:12, Jul 10 & $\begin{array}{c}6 \mathrm{~m}+35 \mathrm{~m} \text { plus } \\
40 \mathrm{~m}+420 \mathrm{~m}\end{array}$ & yes & no & No & $509 \mathrm{~m}$ & - & \\
\hline 9908 & 22:08:25, Jul 10 & $6 m+488 m$ & yes & $\operatorname{rod} 2$ & $F: 2$ & $131 \mathrm{~m}$ & 9 & $>2.8$ \\
\hline 9909 & 10:50:00, Jul 15 & $6 \mathrm{~m}+491 \mathrm{~m}$ & no & - & F: 4, PD: 4 \& - & & & \\
\hline 9910 & 15:59:49, Jul 18 & $6 m+492 m$ & no & - & $\mathrm{F}: \mathrm{e}$ & $117 \mathrm{~m}$ & & \\
\hline 9911 & 16:01:52, Jul 18 & $6 m+497 m$ & yes & $\operatorname{rod} \mathrm{c}$ & $\mathrm{F}: \mathrm{c}$ & $25 \mathrm{~m}$ & 2 & $>6.6$ \\
\hline
\end{tabular}

* F: flashover, PD: parallel discharge, LD: local discharge. 

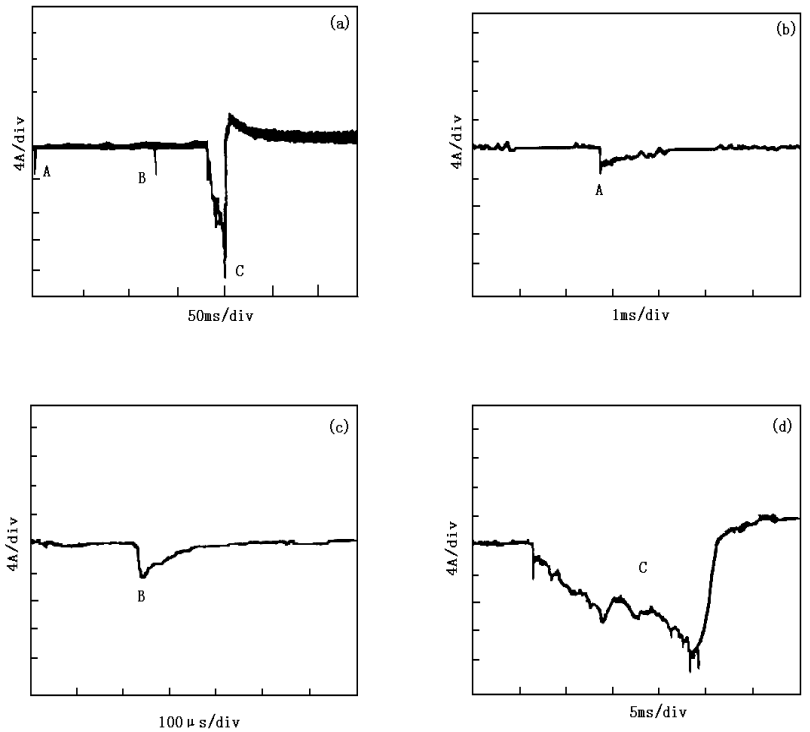

Fig. 5. Currents for event 9910. (a) is the whole waveform and (b), (c) and (d) are expansions of pulses A, B and C in the (a) respectively

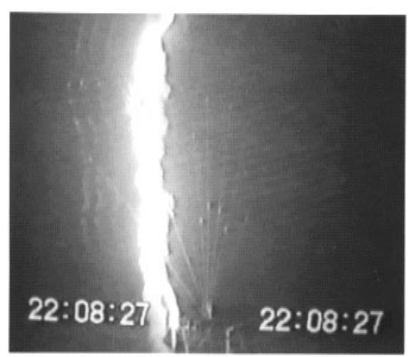

(a)

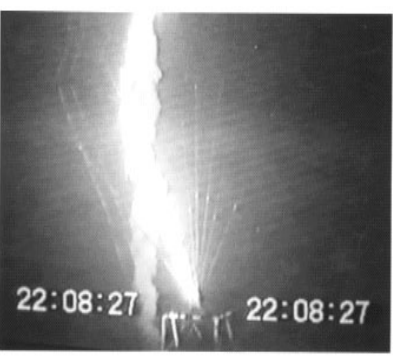

(b)
Fig. 6. Two video pictures for event 9908, showing the lightning firstly struck the steel tower (a) and then the base of the SLE with flashovers along the rod respectively

ms and a peak of 18 amperes, which is in consistent with a charge neutralization of about 0.18 columns (Fig. 5(d)). These current values may be seen, to some extent, as the thresholds for the occurrence of flashover / parallel discharges among the SLE rods. It can be inferred that as the rocket was rising, negative charges were accumulated at the bottom of wire spooled by the rocket and local electric field was intensified. It is this kind of intensive electric field that has triggered spark discharges on the SLE rods. The phenomenon of parallel discharges between SLE rods may be due to the large potential difference between the resistive rods under an intensive electrical field environment.

3.3 Flashover Current through the SLE Flashovers along the SLE rods have been observed for all the 5 events struck the SLE with main discharging channels formed and for 2 out of the 3 events with no main discharging channels. Among the 5 events struck the SLE, current waveforms have been recorded for only the events 9908 and 9911 . A possible reason for no current records is probably that the currents for the other 3 events have flowed into the ground entirely via the tower legs due to flashovers between the SLE and the steel tower.

Figure 6 shows 2 video pictures for the event 9908. The lightning firstly struck onto the steel tower (Fig. 6(a)) and then onto the base of the SLE (Fig. 6(b)). The current waveform recorded has an abnormal shape with a peak of just about 2.8

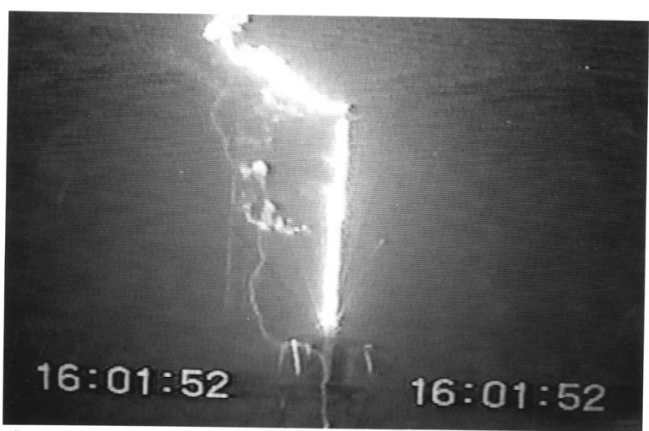

Fig. 7. A video picture for event 9911 , showing the lightning struck the SLE at rod c and the flashover occurred along the rod surface

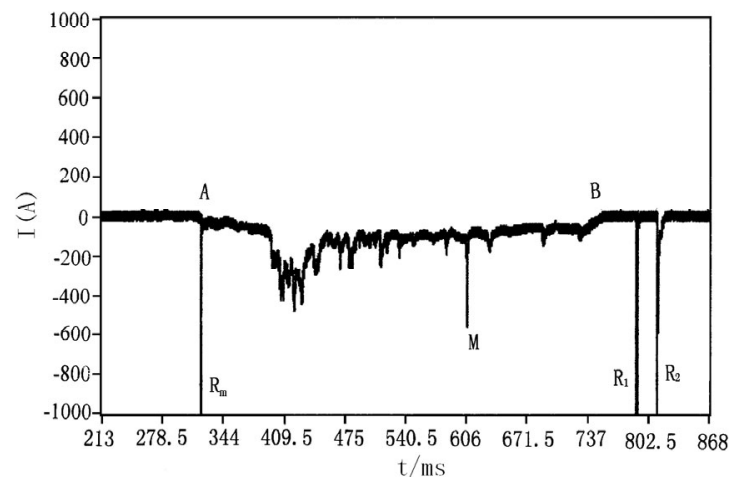

Fig. 8. The current waveform recorded for event 9911

kilo-amperes, probably due to that most of the current has flowed into the ground via the tower legs.

Figure 7 is a video picture of the event 9911 showing the flashovers on the SLE rod c. The whole current waveform recorded for this event is shown in Figure 8. Further expansion of the current waveform shows that the discharge includes a mini-return stroke followed by a continuous current process and two return strokes with a total lasting time of about $500 \mathrm{~ms}^{(10)}$. The mini-return stroke lasts about 3 microseconds with a peak current of 914 amperes, which is corresponding to a neutralized charge of just 1.5 milli-columns. The continuous current process, occurred $100 \mathrm{~ms}$ after the mini-return stroke, lasts about $435 \mathrm{~ms}$ with a peak current of 440 amperes, which is corresponding to a neutralized charge of about 58 columns. Some pulses superposed on the continuous current are believed to be $\mathrm{M}$ components and the largest one has a peak of about 300 amperes. There is a current quiet period of $36 \mathrm{~ms}$ after the continuous current. After that are 2 return strokes occurred successively in a time interval of $21 \mathrm{~ms}$. The first return stroke has a peak current of about 6 kilo-amperes with a front rising time of about 2 microseconds. The second return stroke has a peak current saturated at about 6.6 kilo-amperes. The detailed characteristics derived for these 2 return strokes are in agreement with that in natural lightning ${ }^{(11)}$. The lightning current-limiting function of SLE claimed by its manufacturer has not been confirmed when it was struck by triggered lightning but the flashover phenomenon.

\section{Summary and Discussion Altitude-triggered} lightning experiment aimed to compare the response to lightning of the so-called "Semiconductor Lightning Eliminator (SLE)" with the traditional lightning rod was conducted in 1998. Two out of the 5 succeeded triggered lightning flashes have struck at the 4 
$\mathrm{m}$ high lightning rod with clear attachment processes photographed. None has struck at the $6 \mathrm{~m}$ high SLE system located just $5 \mathrm{~m}$ away from the lightning rod. Nevertheless, some discharging sparks have been observed on the SLE rods when the electric field on ground was more above $-4 \mathrm{kV} / \mathrm{m}$. Such a result shows, at least for these 5 triggered lightning flashes, that the SLE is neither superior to a traditional lightning rod in terms of provision of lightning attachment points and paths for the lightning current to flow into ground, nor capable to eliminate any possibility of lightning within its protection zone. Similar views is given by Uman and Rakov ${ }^{(12)}$ who reviewed critically the nonconventional approaches to lightning protection including various dissipation array systems (DAS) or charge transfer systems (CTS) and early streamer emission (ESE) systems.

Triggered lightning experiment dedicated to test the performance of the SLE was conducted in 1999. Totally 11 triggered lightning events with data recordings have been obtained. Among these 8 events have bright main discharging channels formed with 5 struck the SLE rods. The other 3 events have no main discharging channels formed, however, have caused local spark discharges or flashovers at the SLE rods. Flashovers along the SLE rods have been observed for all the 5 cases struck the SLE and 3 other cases. In addition to flashovers, so-called parallel discharges between two or three SLE rods have been observed for 2 cases struck the SLE and 2 other cases. The phenomena of parallel discharges between and flashovers along the SLE rods are obviously due to the large potential gradient between / along the resistive rods when a current with certain amplitude flows on the SLE rods. Measurements of the current on grounding system of the SLE have been succeeded for only case, probably due to that the current paths in most cases are other than the grounding system because of flashovers. The peak current for one stroke recorded is more than 6.6 kilo-amperes. Similar experiments are those of Horii et al. ${ }^{(5)}$ and Teramoto et al. ${ }^{(6)}$ who tested the performance of the SLE rods and a sort of lightning rod with high resistance by using the triggered lightning technique in fields and the high voltage long-gap discharge technique in laboratories in Japan. Small currents were measured when the flashover did not occur along the surface of the resistance element in one out of four cases. However the initiations of upward leader from the tip of SLE were restrained in some extent and the some characteristics of triggering lightning discharges might be influenced due to the high resistance of the SLE. The experiments are not enough to obtain a certain answer for the effectiveness of the SLE. However, some phenomena observed are very helpful for the understanding of interaction between lightning and air terminals and for the improvement of existing lightning protection approaches.

\section{Acknowledgment}

The work leading to this paper was partly supported by the Ministry of Science and Technology of China (Grand No. 2004DEA71070) and the Research Committee of The Hong Kong Polytechnic University. The authors would like to give thanks to researchers from Guangzhou Institute of Power Test and Wuhan University for their cooperation and helps in the experiments

(Manuscript received March 15, 2005, revised Jan. 26, 2006)

\section{References}

(1) C. X. Chen, G. R. Xie, and Z. F. Xie : "The semiconductor lightning current duration extender (SLE)", Proc. $24^{\text {th }}$ Int. Conf. on Lightning Protection, pp.978-983 (1998)

(2) N. L. Allen, K. J. Cornick, D. C. Faircloth, and C. M. Kouzis : "Tests of the "early streamer emission" principle for protection against lightning", IEE Proc. Sci., Meas. Technol., Vol.145, pp.200-206 (1998)

(3) E. N. Chernov, A. V. Lupeiko, and N. I. Petrov : "Investigation of spark discharge in long air gaps using Pockel's device", Proc. $7^{\text {th }}$ Int. Symp. on High Volt. Eng., Vol.4, pp.141-145, Dresden (1991)

(4) V. R. Avansky, E. N. Chernov, A. V. Lupeiko, and N. I. Petrov : "Experimental investigations of lightning phenomena in laboratory", Proc. $9^{\text {th }}$ Int. Conf. on Atmos. Electr., Vol.3, pp.783-790, St. Petersburg, Russia (1992)

(5) K. Horii, K. Nakamura, Y. Ikeda, et al. : "Approach of current limiting lightning rod", Proc. IEEJ, HV-93-59 (1993)

(6) M. Teramoto, T. Yamada, K. Nakamura, et al. : "Triggered lightning test to a new type lightning rod", Proc. Int. Conf. on Elect. Eng., Vol.2, pp.66-70 (1996)

(7) C. B. Moore, W. Rison, J. Mathis, et al. : "Lightning rod improvement studies", J. Appl. Meteorology, Vol.39, pp.593-609 (2000)

(8) V. A. Rakov, et al. : "New insights into lightning processes gained from triggered-lightning experiments in Florida and Alabama", J. Geophys. Res., Vol.103, pp.14117-14130 (1998)

(9) M. Chen, T. Watanabe, N. Tagaki, Y. Du, D. Wang, and X. Liu : "Simultaneous observations of optical and electrical signals in altitude-triggered negative lightning flashes", J. Geophys. Res., Vol.108 (D8), 4240, doi:10.1029/2002JD002676 (2003)

(10) Y. J. Zhang, X. S. Liu, C. W. Wang, et al. : "Study on the characteristics of positive and negative leader in triggered lightning in altitude", Plateau Meteorology, Vol.20, pp.6-13, 2001 (in Chinese)

(11) M. A.Uman : The lightning discharge, pp.138-139, Academic Press, Inc. (1987)

(12) M. A. Uman and V. A. Rakov : "A critical review of nonconventional approaches to lightning protection", American Meteorological Society, DOI:10,1175/BAMS-83-12-1809 (2002)

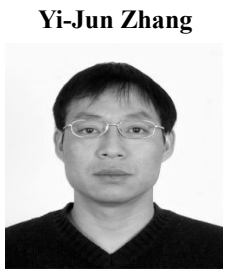

(Non-member) $\mathrm{He}$ was born in Hebei, China, in December of 1963. He received a $\mathrm{Ph}$. D degree in atmospheric physics from Lanzhou Institute of Plateau Atmospheric Physics in 1997, and is presently a Professor at Chinese Academy of Meteorological Sciences. He has worked on atmospheric Science, and lightning physics.

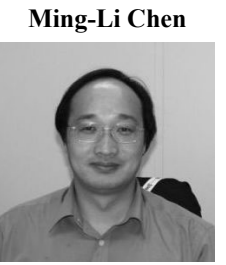

(Non-member) He was born in Shanxi, China, in December of 1964. He received a Ph. D. degree in electronic and information system from Gifu University, Japan, 2000, and is presently an assistant professor at The Hong Kong Polytechnic University. He has worked on lightning physics, power quality and electrical services.

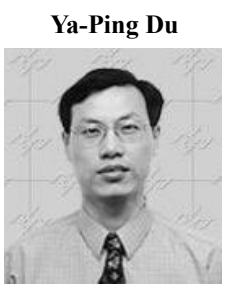

(Non-member) He was born in Shanghai, China, in 1962, received a Ph. D. degree in electrical engineering from University of Southern California, USA, in 1994, and is presently an associate professor at The Hong Kong Polytechnic University. He has worked on EMC, power quality and lightning protection in buildings

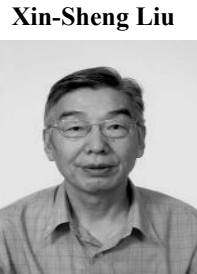

(Non-member) He was born in Henan, China, in June of 1938. He graduated from Lanzhou University in 1959 with a Bachelor degree in physics. Since 1974, he has been working at Lanzhou Institute of Plateau Atmospheric Physics, and is presently a Professor at the institute. He has worked on atmospheric physics. 